\title{
Empowering women in the maritime community
}

\author{
Momoko Kitada $^{1} \cdot$ Laura Carballo Piñeiro $^{1} \cdot$ Maximo Q. Mejia Jr ${ }^{1}$
}

Published online: 25 November 2019

(C) World Maritime University 2019

\section{Introduction}

It was not long ago when the maritime community was narrated in masculine forms of language. Seamen, helmsman, and fishermen are just a few examples of professional roles assumed to be filled by men. What is assumed to be common or ordinary in the maritime community has been reflected by an enduring tradition of treating seafaring and other sea-related activities as an exclusively male domain. ${ }^{1}$ Such a norm is no longer considered "natural" in today's maritime community. As highlighted in the "Foreword" by the World Maritime University (WMU) President Cleopatra Doumbia-Henry, the Maritime Labour Convention 2006 sets out gender neutrality by eliminating gender-biased terms in its text that would otherwise assume, for instance, that all seafarers are men. However, the French and the Spanish versions of the Convention are not as neutral as the English one being a reminder of how fragile gender equality even as an objective is.

The fair recognition of women's contribution to the maritime industry is considered to have its roots in 1988 when the International Maritime Organization (IMO) launched its Integration of Women in the Maritime Sector (IWMS) program. ${ }^{2}$ IMO SecretaryGeneral Kitack Lim's announcement of the World Maritime Day (WMD) 2019 theme, "Empowering Women in the Maritime Community," demonstrates the Organization's dedication to gender equality even today. Echoing this focus, the WMU hosted the Third WMU International Women's Conference on Empowering Women in the

\footnotetext{
${ }^{1}$ Kitada, M., Williams, E., \& Froholdt, L. L. (2015). Maritime Women: Global Leadership. Heidelberg: Springer.

${ }^{2}$ Tansey, P. (2015). Women at the Helm: 25 Years of IMO’s Gender Programme. In M. Kitada, E. Williams, \& L. L. Froholdt (Eds.), Maritime Women: Global Leadership. Heidelberg: Springer.
}

Momoko Kitada

mk@wmu.se

Laura Carballo Piñeiro

1c@wmu.se

Maximo Q. Mejia, Jr

mm@wmu.se

1 World Maritime University, Malmö, Sweden 
Maritime Community, at Malmö, Sweden, from 4 to 5 April 2019 to address the gender gap and the lack of visibility of women work in maritime, oceans, ports, ocean science, fishing, and seafood harvesting. The Conference attracted over 350 participants from more than 70 countries around the globe, who actively participated in discussions and drew a set of conclusions ${ }^{3}$ for the development and implementation of genderresponsive policies and related programs in their respective sectors and areas of responsibility.

The Conference has delivered four major outcomes: (1) a set of conclusions; (2) IMO document (TC 69/10/2) ${ }^{4}$; (3) the Conference Report; and (4) the WMU Journal of Maritime Affairs (JoMA) Special Issue on Empowering Women in the Maritime Community. This special issue is WMU's academic and scientific outcome to advance knowledge on gender equality in the maritime and ocean communities. The Call for Papers attracted 45 abstracts from both female and male authors in 23 countries (8 Asian, 3 North American, 2 South American, 3 Caribbean, 3 Middle Eastern, 2 African, and 24 European), from which 16 were selected for oral presentation at the conference. Out of the 42 accepted abstracts, 18 full papers were submitted to JoMA. Only 14 papers proceeded to peer review by guest editors and finally six papers met the standards of JoMA for publication.

\section{Gender and maritime studies}

Gender perspectives in the maritime community is an important interdisciplinary research area that can contribute to effectiveness in maritime operations and management. The ILO-commissioned book, Women seafarers: global employment policies and practices, published in 2003 is an early worldwide publication on gender issues in shipping. This book is still well-cited because of the lack of global data on women seafarers. Another major publication at the global level is Maritime Women: Global Leadership based on the Second WMU International Women's Conference held in 2014. The lack of global data on the extent and quality of women's participation in the maritime and ocean communities was highlighted at the Third WMU International Women's Conference, which urged all stakeholders to make such data and information available. This JoMA special issue on Empowering Women in the Maritime Community will be another addition to the literature on gender research in the maritime industry.

Within maritime gender studies, the available literature covers gender issues in terms of maritime education and training (see the ITF-funded GEM project ${ }^{5}$ and the IAMU

\footnotetext{
${ }^{3}$ https://www.wmu.se/sites/default/files/documents/files/Final\%20conclusion_3rd\%20WMU\%20women $\% 27$ s\%20conference.pdf

${ }^{4}$ Document no.: TC 69/10/2 (Report of the Third WMU International Conference: Empowering Women in the Maritime Community) was noted by the Secretariat during the $69^{\text {th }}$ session of the Technical Cooperation Committee meeting at IMO under the agenda item 10: Capacity-Building: Strengthening The Impact of Women in the Maritime Sector.

held in Malmö, Sweden, from 4 to 5 April 2019

${ }^{5}$ Pike, K. et al. (2016). The Gender Empowerment and Multi-cultural Crew (GEM) Project Report, 20152016. Solent University.
} 
research project ${ }^{6}$ ), occupational health and safety (see the women seafarers' health survey $^{7}$ ), gender discrimination and sexual harassment, ${ }^{8}$ policies, ${ }^{9}$ identities, ${ }^{10}$ culture, ${ }^{11}$ leadership, ${ }^{12}$ careers and work-life balance, ${ }^{13}$ social theories, ${ }^{14}$ and others. These studies are indeed helpful to understanding how maritime jobs are designed and gender biases are reproduced, thereby shaping our thoughts and behaviors. On the one hand, our world is rapidly changing toward digitization and low carbon footprint and we are expected to adapt to such technological and behavioral changes. Maritime gender studies will be also required to consider a new paradigm of maritime transportation and WMU's role is clearly to lead gender research in the maritime and ocean communities and to support better policy-making for gender equality-Goal 5 of the United Nations Sustainable Development Goals (UNSDGs).

\section{Furthering gender in maritime and ocean research}

The Third WMU International Women's Conference bridged various maritime and ocean fields to facilitate interdisciplinary research on gender in maritime and ocean sciences. A set of conclusions also highlights a clear need for gender research and funding. During the conference, a new research project entitled "Empowering Women for the United Nations Decade of Ocean Science for Sustainable Development" was announced by the Department of Fisheries and Oceans Canada. The 3-year project will fund one post-doc researcher and two PhD students under the WMU-Sasakawa Global Ocean Institute.

\footnotetext{
${ }^{6}$ Dragomir, C. et al. (2018). Gender Equality and Cultural Awareness in Maritime Education and Training, Final Report for the FY2017 IAMU Capacity building Project. Tokyo: IAMU.

${ }^{7}$ International Maritime Health Association, International Seafarers' Welfare and Assistance Network, International Transport Worker's Federation and Seafarers Hospital Society. (2015). Women Seafarers' Health and Welfare Survey. Croydon: International Seafarers' Welfare \& Assistance Network.

${ }^{8}$ Almost all the gender research in the maritime industry touch upon gender-based discrimination and sexual harassment. The International Chamber of Shipping (ICS) and the International Transport Workers' Federation (ITF) jointly published the Guidance on eliminating shipboard harassment and bullying in 2016. It triggered the recent amendment of MLC, 2006, on this matter, which was adopted in 2016.

${ }^{9}$ A number of literature discuss gender policies as part of their data analysis and discussions; however, one useful source will be a book chapter on key legal instruments for maritime women as well as corporate social responsibility (CSR) which voluntarily promotes gender equality in shipping: Kitada, M., \& Tansey, P. (2018). The CSR in the maritime industry. In L. L. Froholdt (Ed.), Corporate Social Responsibility in the Maritime Industry. Cham: Springer. In the context of the Law of the Sea, see Papanicolopulu, I. (Ed.) (2019). Gender and the Law of the Sea. Leiden: Brill.

${ }^{10}$ Kitada, M. (2010). Women Seafarers and their Identities. (PhD thesis). Cardiff University, Cardiff.

${ }^{11}$ See the GEM project as a gender study in the context of multicultural crews and Kitada (2010) who discusses the occupational culture of seafaring and gender.

${ }^{12}$ Kitada, M., Williams, E., \& Froholdt, L. L. (2015). Maritime Women: Global Leadership. Heidelberg: Springer.

${ }^{13}$ See for instance, Bhirugnath-Bhookhun, M., \& Kitada, M. (2017). Lost in success: women's maritime careers in Eastern and Southern Africa. Communications, 1-10. doi:10.1057/palcomms.2017.23 and Kitada, M., \& Harada, J. (2019). Progress or regress on gender equality: The case study of selected transport STEM careers and their vocational education and training in Japan. Transportation Research Interdisciplinary Perspectives(1). doi:https://doi.org/10.1016/j.trip.2019.100009

${ }^{14}$ Kitada, M., \& Langåker, L. (2017). "The Body" Matters in Maritime Employment Contracts. Paper presented at the International Association of Maritime Universities (IAMU) General Assembly, Varna.
} 
This special issue features one guest paper and six peer-reviewed research articles with a great diversity in the geographical distribution of authors (Brazil, Indonesia, Mauritius, Norway, Portugal, Spain, Sweden, and Trinidad and Tobago) and specialized fields of work within maritime and ocean communities.

In his guest paper, Vasco Becker-Weinberg provides an important insight into gender implications in illegal, unregulated, and unreported (IUU) fishing. He discusses the invisibility of women and girls as victims of abuse in IUU fishing. The paper addresses SDG 5, Goal 5.2 ("End all violence against and exploitation of women and girls"). Becker-Weinberg teaches law of the sea and ocean governance subjects, as well as public international law, and has researched at prominent academic institutions and written and published extensively. He often advises on law of the sea matters and on policies and legislation on many ocean governance subjects, for both public and private entities. He has recently taken on an important consultancy assignment for the ILO, on the connection between human trafficking and IUU fishing.

In her article, titled "Maritime Security Strategies from a Gendered Perspective: Implications for the Development of United Nations SDG 5," Isabel Lirola-Delgado focuses on the European Union Maritime Security Strategy and the Spanish National Maritime Security Strategy as examples of the invisibility of the gender dimension, and suggests means of enhancing the gendered perspective in the stated strategies. Her contribution is relevant to SDG 5, Target 5.C ("Adopt and strengthen policies and enforceable legislation for gender equality").

Sabrina Evangelista Medeiros, Fabiana Abreu do Valle Ventura Piassi, and Rita de Cassia Oliveira Feodrippe conceptualize the challenges of women in the Brazilian Navy by adopting feminist theories in their article titled "Mapping Women's Presence and Importance in the Brazilian Maritime Community." The invisibility of women in the workforce in the Brazilian maritime community is evident from the study. The work relates to SDG 5, Target 5.1 ("End discrimination against women and girls") among other targets.

Tae-eun Kim, Amit Sharma, Anne Haugen Gausdal, and Chong Ju Chae present an article entitled "Impact of autonomy on gender parity in maritime industry." They present their investigation into whether disruptive changes with regard to autonomy will lower the barriers to employment opportunities for women seafarers/operators in the merchant shipping industry. The findings from the study can shed light on the means to achieving gender parity in the maritime industry and help address the strategic directions of the IMO and the UN SDGs. Their article is particularly relevant to SDG 5, Target 5.B ("Promote empowerment of women through technology").

In her article titled, "Building Business, Enriching Lives: An Indonesia Initiative to Empower Women in the Fishing Communities," Setyawati Fitrianggraeni shares a business cooperative (Indonesian Koperasi) model that not only energizes community life with women as its driving force but also enhances maritime safety and security by making the family aware of the professional risks. The scope of this article relates to SDG 5, Target 5.A ("Equal rights to economic resources, property ownership and financial services").

Sarita Thalini Mahabir-Lee and Vivian Radha Rambarath-Parasram present various international and regional efforts by laws and programs for the empowerment of women in the Caribbean maritime community. Their article titled "Forging ahead leveraging inclusive and equitable education to bridge the gender gap in the Caribbean" 
addresses the important role of maritime education and training in the achievement of SDG 5. The key message from the article relates to SDG 5, Target 5.C ("Adopt and strengthen policies and enforceable legislation for gender equality").

Finally, the article by Momoko Kitada and Meenaksi Bhirugnath-Bhookhun assesses the application of Rapid Integrated Assessment (RIA) as a tool to increasing gender equality in maritime clusters. Their article, "Beyond business-as-usual: The role of women professionals in maritime clusters," indicates the usefulness of RIA in identifying the gender gap and helps determine where to build capacity in selected maritime clusters in Japan, Norway, and Singapore. This article contributes to SDG 5, Target 5.5 ("Ensure full participation in leadership and decision-making").

\section{Concluding remarks}

The JoMA special issue on Empowering Women in the Maritime Community is a continued effort by WMU to promote gender studies in the maritime and ocean communities, nearly five years after the third volume of the WMU Book Series, "Maritime Women: Global Leadership." In the last five years, the landscape of maritime research surrounded by women and men has been changed by various factors, such as the growing attention to oceans research, ${ }^{15}$ the impact of digitization on maritime jobs, ${ }^{16}$ and low/zero emissions from ships and ports. ${ }^{17}$ In this JoMA special issue, interdisciplinary research to bridge gender and sustainability issues in the maritime and ocean communities was emphasized across the articles. As indicated in the Call for Papers, the collection of research articles also addresses evidence-based policy implications in the following targets within Goal 5: Targets 5.1 ("End discrimination against women and girls"), 5.2 ("End all violence against and exploitation of women and girls"), 5.5 ("Ensure full participation in leadership and decision-making"), 5.A ("Equal rights to economic resources, property ownership and financial services"), 5.B ("Promote empowerment of women through technology"), and 5.C ("Adopt and strengthen policies and enforceable legislation for gender equality").

Throughout the call for papers, which attracted a total of 45 abstracts, it was noticeable that research contributions from the Pacific $(n=0)$ and Africa $(n=2)$ were scarce. Contributions from the Caribbean $(n=2)$ and the Middle East $(n=3)$ were also low, while the contribution from Europe $(n=24)$ represented more than half of the total submissions. This is problematic from the WMU perspective of capacity building in research across the different corners of the globe. It is unclear whether these regions produce less research in maritime and ocean sciences in general or whether the tendency is specific to gender research in maritime and ocean communities. In either case, gender studies should continue to be encouraged in all countries, but especially in the Pacific, Africa, Middle East, and Caribbean regions. If a country does not produce data and information through research, it will be excluded (or even considered to be non-existent) from the world's knowledge. Invisibility of the country's profile would

\footnotetext{
${ }^{15}$ Relevant to SDG 14 (oceans).

${ }^{16}$ Relevant to SDG 8 (decent work) and 9 (industry, innovation and infrastructure).

${ }^{17}$ Relevant to SDG 7 (clean energy), 12 (responsible consumption and production), 13 (climate action).
} 
negatively affect its economy and development; hence, research is of utmost importance.

The special issue guest editors would like to thank the scientific contribution by Vasco Becker-Weinberg, NOVA School of Law, Portugal, as an invited contributor, Irini Papanicolopulu, Università di Milano-Bicocca, and WMU faculty members including Raphaël Baumler, Monica Canepa, Ronán Long, Aykut I. Ölçer, Satya Sahoo, and Dong-Wook Song, who supported this special issue. Our sincere appreciation goes to all anonymous reviewers of the submitted manuscripts for their valuable feedbacks in ensuring the quality of the articles. Finally, the guest editors extend their special thanks to WMU President Cleopatra Doumbia-Henry who guided all the key conference deliverables as well as contributing the "Foreword" for this special issue.

Publisher's note Springer Nature remains neutral with regard to jurisdictional claims in published maps and institutional affiliations. 